\begin{tabular}{|c|c|c|}
\hline $\begin{array}{l}\text { PKS } \\
\begin{array}{l}\text { PUBLLC } \\
\text { KNDLEDEDE } \\
\text { PROJECT }\end{array}\end{array}$ & $\begin{array}{l}\text { Revista de GEOGRAFIA } \\
\text { (RECIFE) } \\
\text { http://www.revista.ufpe.br/revistageografia }\end{array}$ & $\begin{array}{l}\text { OJS } \\
\begin{array}{l}\text { OPEN } \\
\text { JOUNAL } \\
\text { SYSTEMS }\end{array}\end{array}$ \\
\hline
\end{tabular}

\title{
GEOMORFOLOGIA DE DUNAS COSTEIRAS PRIMÁRIAS E SECUNDÁRIAS DETERMINADAS POR IMAGENS DE ALTA RESOLUÇÃO
}

\author{
Guilherme Borges Fernandez ${ }^{1}$
}

\begin{abstract}
${ }^{1}$ Laboratório de Geografia Física - LAGEF.Departartamento de Geogragia, Instituto de Geociências. Universidade Federal Fluminense -UFF.Email: guilhermefernandez@id.uff.br
\end{abstract}

Artigo recebido em 22/07/2018 e aceito em 23/08/2018

\begin{abstract}
RESUMO
Dunas costeiras apresentam padrões morfológicos bastente diversos, influenciados por fatores como efeitos de obstáculos como por exemplo a vegetação ou então as formas se definem livremente a partir dos processos de transporte e deposição. Dessa forma, diferentes trabalhos tem com relativo sucesso, classificar morfologicamente as dunas observadas ao longo da costa. De forma relativamente simples, dunas formadas a partir do transporte de sedimentos a partir da praia e depositados no pós praia são consideradas dunas primárias. A partir desta primeira formação, a ação subsequente do vento acaba gerando dunas secundárias. Neste trabalho foram mostrados os avanços que novas tecnologias associadas a levantamentos aerotransportados obtidos por veículos aéreos não tripulados (VANT), permitiram uma avaliação morfológica mais detalhada das nuances que a ação do vento registrou em dunas primárias e secundárias. Os resultados mostraram que a utilização dos dados do VANT, processadas por métodos tradicionais de aerofotogrametria permitiram a interpretação de diferentes formas de relevo, anteriormente mascaradas ou inexistentes em relação a interpolação de dados altimétricos obtidos por GPS geodésico. De maneira geral, pode-se concluir que para feições geomorfológicas com alta complexidade morfológia, como dunas costeiras, a utilização do VANT se mostra ainda uma fronteira a ser explorada. Palavras-chaves: Processos Eólicos, Veículo Aéreo Não Tripulado (VANT), Modelos morfológicos.
\end{abstract}

\section{PRIMARY AND SECUNDARY COASTAL DUNES DETERMINED BY HIGH-RESOLUTION IMAGES}

\begin{abstract}
Coastal present different morphological patterns, influenced by factors as vegetation or can be development as free dunes, associated by sediment transport and deposition. Considering this, some works classify coastal dunes, with relative success, using morphological models, applied to coastal dunes. In simple way, primary coastal dunes are formed by directly sediment transport from the beach to the backshore. The wind action in the primary dunes, form the secondary coastal dunes. In this work, we show the advances, in terms of high-resolution morphological data, about patterns and details observed in primary and secondary dunes. The results showed that UAV data obtained was crucial to understand and interpreted, different morphological patterns, compared by other methodologies, as geodesic GPS interpolation points. We conclude the high diverse morphological characteristcs in coastal dunes is possible to be better understanding using UAV images, and it is a frontier to be explored by geomorphologists.

Keywords: Aeolian Process, Unmanned Air Vehicle (UAV), Morphological Models.
\end{abstract}




\section{INTRODUÇÃO}

A geomorfologia se desenvolveu nos últimos dez anos fundamentalmente atrelada a incorporação de novas tecnologias que permitiram, a partir de um forte incremento na aquisição de dados, gerarem não somente uma profunda ampliação e melhores explicações sobre como que as diferentes formas de relevo se distribuem na superfície terrestre, mas principalmente pela possibilidade de formulações de novas questões sobre processos geomorfológicos, formas, e escalas de análise (Viles, 2015). Alguns autores como Piégay et al (2015) sugere que de fato existe uma revolução tecnológica, em que a partir de técnicas não invasivas como investigações em subsuperfície, associadas a determinação de dados morfológicos, permitiram avanços sistemáticos em estudos geomorfológicos, principalmente para se determinar a interrelação entre diferentes escalas espaciais e temporais. $O$ tema que relaciona diferentes escalas espacias e temporais foi recentemente discutido por Ewing et al (2015), que com dados de estudos que mostram formas de relevo associadas ao vento, descritas desde morfologia auto-organizadas em escalas de detalhe, até formas distribuídas regionalmente. Estes estudos dão suporte a análises relacionadas por exemplo, ao impacto que o regime de ventos exerce sobre as formas eólicas, ou memo aspectos relacionados ao suprimento sedimentar para as dunas. Independentemente da escala de análise, o detalhamento geomorfológico é fundamental para que a interpetação de formas e de processos eólicos.

No particular em relação a determinação morfológica de alta definição, Viles (2015) identifica que a utilização de veículos aéreos não tripulados (VANTs) representam um dos principais elementos de avanço tecnológico, para determinação de morfologia de alta resolução, desde escala métrica a submétrica. Particularmente estudos que se dedicaram a interpretar aspectos fisiográficos relacionados ao vento, tem se beneficiado sobremaneira da utilização de VANTs. Tal afirmação é ilustrada por exemplo nos trabalhos de Zhao et al (2018), que combinou imagens Landsat com detalhamentos fisiográficos obtidos com VANT, que permitiram a observação de formas anteriormente mascaradas, pela baixa resolução das imagens. Ruelssink et al (2018), fundamentou estudos de recuperação de dunas frontais, com estudos detalhados por imagens de alta resolução, para manejo e recomposição florística na costa holandesa. Também na costa holandesa, Nolet et al (2018) utilizando imagens obtidas por camêras aerotransportadas, identificou diferentes padrões de vegetação para estudos de recuperação vegetal. Estes exemplos, ilustram que recentemente, em áreas submetidas a ação dos ventos, os VANTs foram fundamentais na investigação de processos e formas eólicas. 
Neste sentido este trabalho tem como objetivo fundamental apresentar resultados de detalhamento morfológico, obtidos por VANT, em dunas costeiras primárias e secundárias, obtidos no litoral do estado do Rio de Janeiro. As áreas onde as dunas costeiras ocorrem de maneira marcante na pasiagem estão estabelecidas entre Saquarema e Arraial do Cabo, na planície costeira da Massambaba, conforme a figura 1 e as planícies costeiras de Cabo Frio e Peró (Figura 2). Ambas as áreas são submetidas mais fortemente por ventos de direção NE, em quase todo o ano, e de maneira mais esparsa, a ventos do quadrante sul oriundos de frentes frias (Fernandez et al, 2017). A planície costeira da Massambaba foi recentemente descrita morfologicamente por Figueiredo et al (2018), que interpretou em diferentes áreas, a ação eólica retrabalhando sedimentos formadores de um duplo sistema de barreiras costeiras, de maneira que a ação dos ventos foi identificada não somente na barreira interna, com também na barreira externa. Nas áreas de Cabo Frio e Peró, Fernandez et al (2017) demonstraram que existem uma forte presença de depósitos associados ao vento, discriminando diferentes padrões morfológicos. O que se pode assumir em ambas as áreas é que a ação eólica pode estar diretamente associada a dunas formadas adjacentes a praia, resultando em depósitos eólicos costeiros primários, ou dunas formadas a partir de sedimentos depositados de maneira preexistente, ou seja derivados das dunas primárias ou em épocas geológicas passadas, formando dunas secundárias.
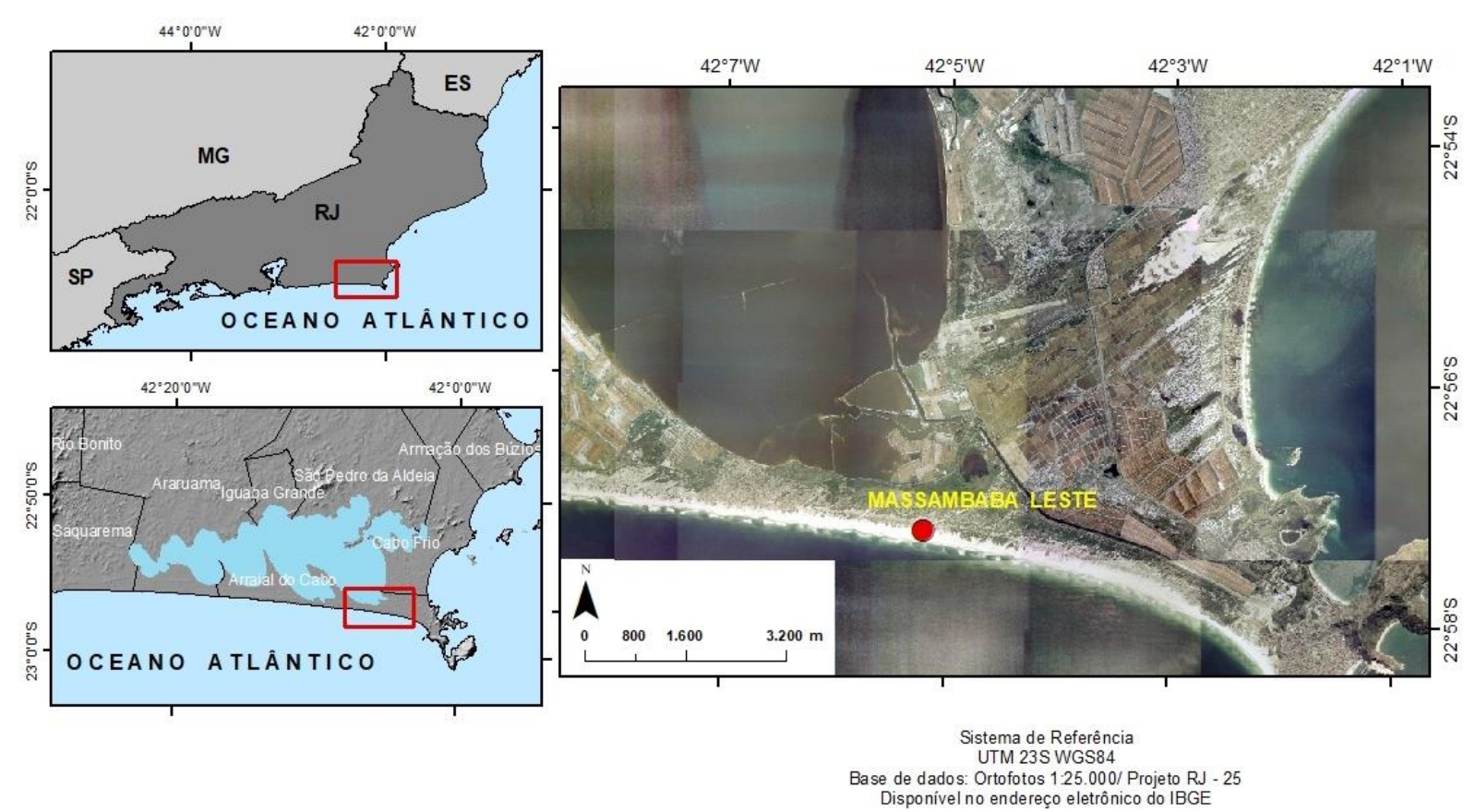

Figura 1. Planície costeira da Massambaba, o ponto de referência em vermelho destaca a área onde foram obtidos os dados com VANT. 


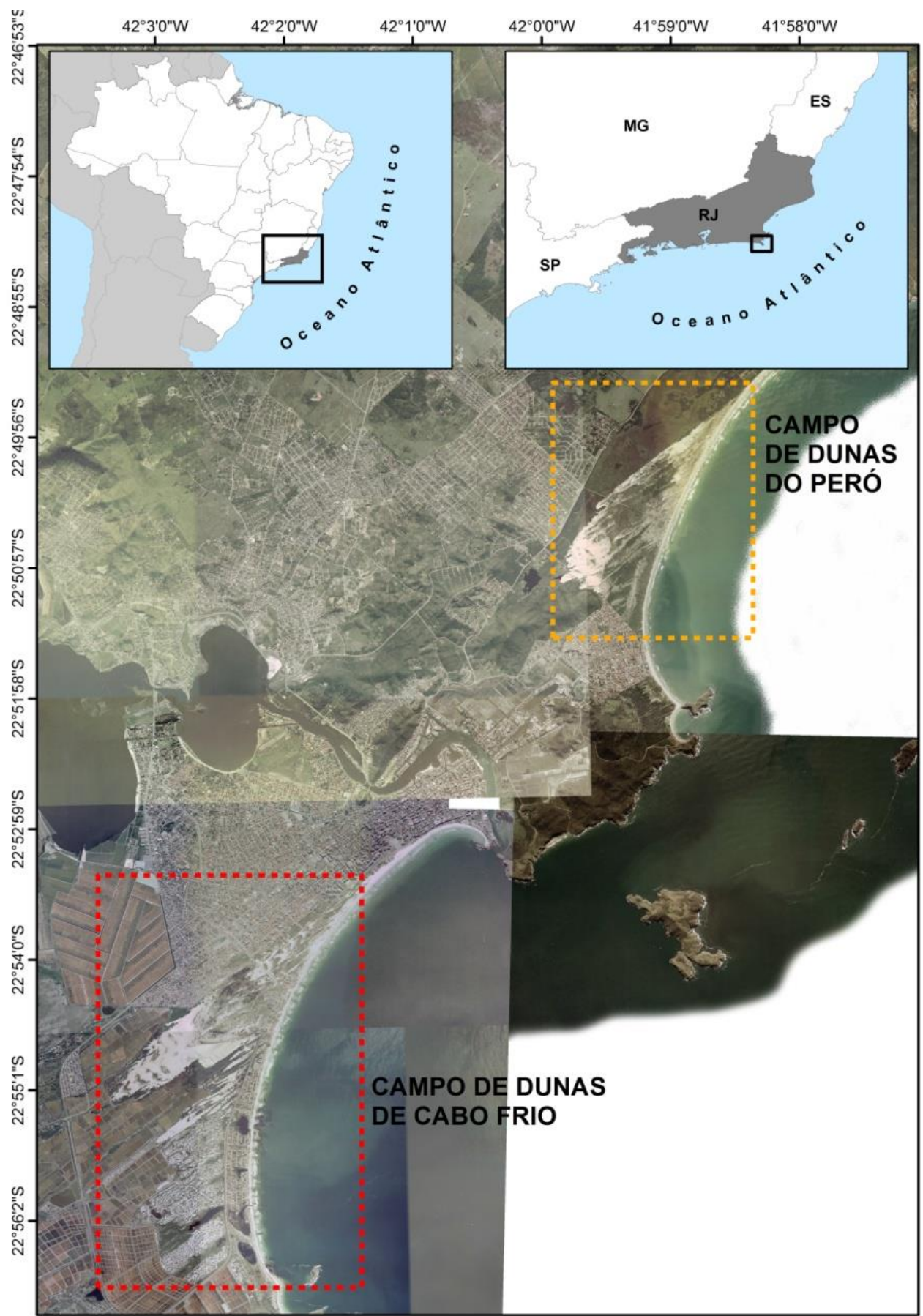

Figura 2. Planícies costeiras de Cabo Frio e Peró. Estas áreas se destacam pela ocorrência de diferentes formas eólicas.

\section{CONSIDERAÇÕES SOBRE DUNAS COSTEIRAS PRIMÁRIAS E SECUNDÁRIAS}

A definição de dunas primárias está diretamente associada a depósito eólicos derivados de sedimentos depositados na praia e removidos pela ação eólica, em direção ao pós-praia. Essa nomenclatura foi primeiramente proposta por Davis (1980), que sugeriu que a sedimentação erodida da praia, seria fixada principalmente por efeito da vegetação. Hesp 
(2002) sugere que dunas formadas por efeito da vegetação assumiriam a nomenclatura de dunas frontais (foredunes), assim em português o termo foredunes, normalmente é traduzido por dunas frontais. O que se assume aqui neste artigo é, conforme o próprio Hesp (2002) interpreta, dunas frontais (foredunes) seriam sinônimo de dunas adjacentes a praia, formadas por aprisionamento sedimentar por efeito de vegetação. Pode-se então interpretar que nem todas as dunas formadas adjacentes a praia, são dunas frontais. Outras tipologias podem ser observadas, como dunas transversais, barcanas e barcanóides, por exemplo (Sloss et al 2012). As dunas adjacentes às praias, portanto podem assumir diferentes feições, dependendo de fatores como por exemplo suprimento sedimentar, alinhamento da linha de costa, granulometria, efeito de obstáculos e principalmente a vegetação.

Uma vez formadas adjacentes à praia, a contínua ação do vento pode resultar em retrabalhamento dos sedimentos depositados junto à costa, formando sequencias eólicas associadas a dunas secundárias, e portanto sem estarem diretamente ligadas a processos costeiros associados a morfodinâmica de praias (Davis, 1980). De forma mais comum, associa-se a dunas secundárias a formas de relevo derivados das dunas primárias, como por exemplo, cortes eólicos e dunas parabólicas, ou mesmo quaisquer depósitos eólicos transgressivos que não estejam conectados diretamente a sedimentação praial (Sloss et al 2012). Sloss et al (2012) reforça que parabólicas ou mesmo dunas, como por exemplo barcanas, barcanóides e transversais, caso estejam conectadas a praia, estas passam a ser consideradas dunas primárias. Desta forma, utilizando a classificação aplicada a dunas costeiras primárias ou secundárias, estas se diferenciam pela incorporação direta de sedimentos (primárias) ou resultante do retrabalhamento de sedimentos pré depositados, como secundárias, e não está relacionada a morfologia específica do depósito eólico. A figura 3 ilustra algumas formações primárias - dunas frontais - formadas por sedimentos oriundo da praia e fixos por vegetação, e alguns exemplos observados de dunas secundárias, como cortes eólicos, formados a partir do rompimento da estabilidade da vegetação por rajadas de vento, e dunas parabólicas, estas formadas na planície costeira, por sedimentos depositados em previamente. 


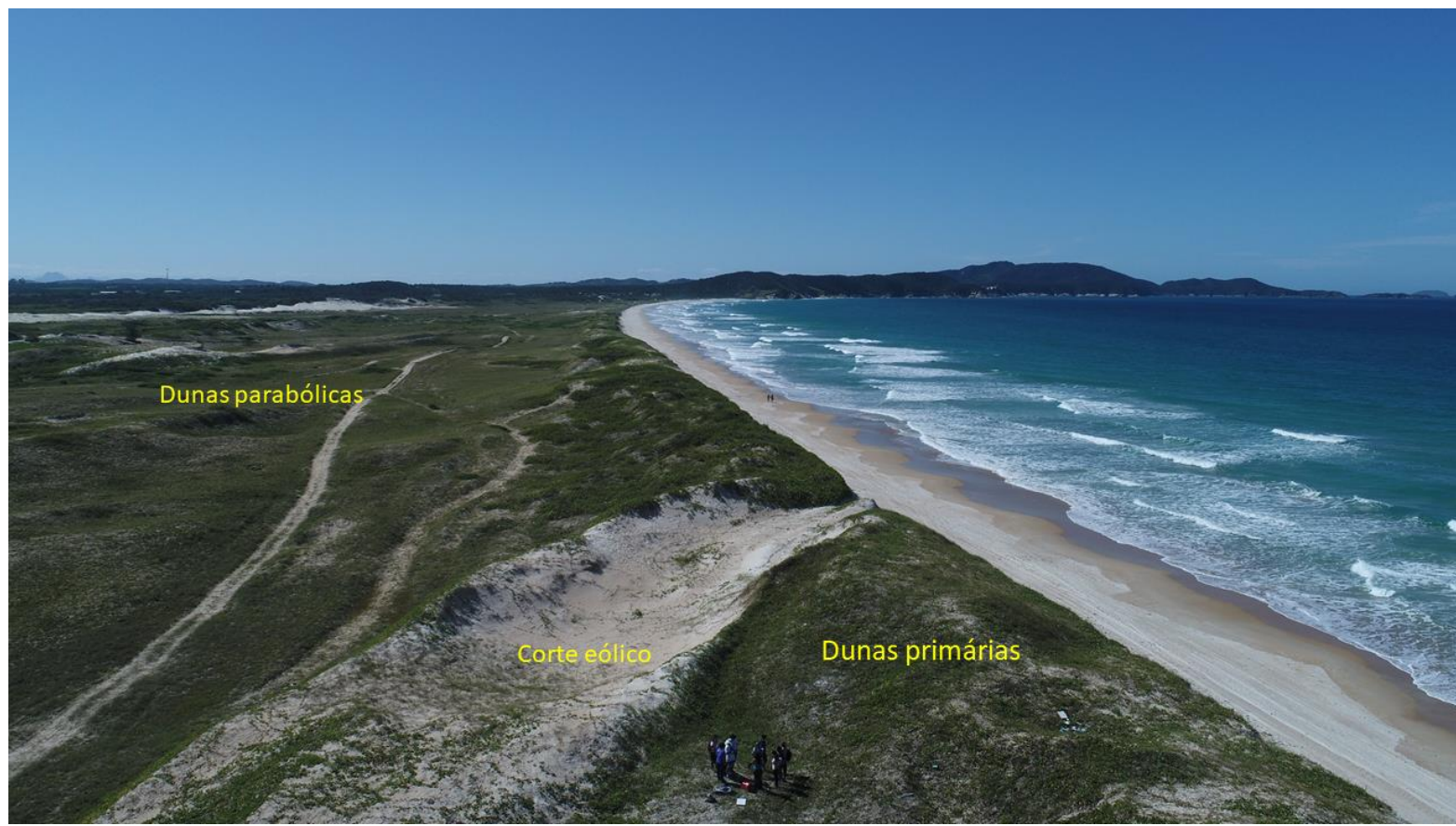

Figura 3. Exemplo de dunas primárias (dunas frontais) e secundárias (cortes eólicos e parabólicas) a partir de fotografia oblíqua obtida na Planície Costeira do Peró.

\section{MORFOLOGIA DE DETALHE OBSERVADAS POR VANT EXTREMO ORIENTAL DA MASSAMBABA}

O extremo leste da planície costeira da Massambaba (Figura 1) é marcada por uma barreira costeira holocênica, separada por uma depressão, em relação a barreira interna, em que ambas estão submetidas a ação eólica. Os ventos em condições de tempo bom vem de direção NE, e são percentualmente os mais representativos ao longo do ano, soprando de direção terra-mar (offshore winds), em função do alinhamento leste-oeste da linha de costa, conforme afirmações de Fernandez e Muehe (2004). Mesmo em condições desfavoráveis para a formação de depósitos eólicos, Fernandez e Muehe (2004) e Fernandez et al (2016) identificaram tais depósitos, como característicos de dunas frontais, ou seja acumulados por vegetação. A morfologia identificada mostrou acumulações isoladas por ventos terra-mar, e em função de retrabalhamento destes depósitos por ventos offshore, deram origem a dunas parabólicas, com a face de avalanche projetada em direção ao oceano, desta forma o resultado seria a formação de dunas secundárias, em função deste retrabalhamento. As dunas frontais são intercalda por depressões, que funcionam como corredores de transporte de sedimentos, em direção ao reverso das dunas, que em condições de tempestade (Martins e Fernandez, 2018), conseguem suplantar a altura da berma, projetando sedimentos para o reverso das dunas (Fernandez et al 2016; Fernandez e Muehe, 2004). 
Os dados morfológicos obtidos com o VANT (Figura 4), confirma as alegações relativas a morfologia da área previamente feitas, mas estes dados se mostraram sensivelmente mais detalhados e podem abrir novas perpectivas e interpretações fisiográficas. Na figura 4, com o auxílio da seta vermelha, se nota que os ventos de direção NE, estão retrabalhando sedimentos depositados na barreira interna, formando dunas parabólicas, que estão preenchendo a depressão entre as barreiras. Provavelmente a ação dos ventos sobre os depósitos na barreira interna, agem formando cortes eólicos que depois serão depositados na depressão entre as barreiras. Pelo detalhamento morfológico obtido, na parte referente às dunas adjacentes a praia, se nota que de fato as irregularidades topográficas, sugerindo variações na direção do vento, gerando dunas primárias e secundárias e as depressões formadas entre as acumulações por vegetação, formando os corredores da ação de ondas de tempestade.
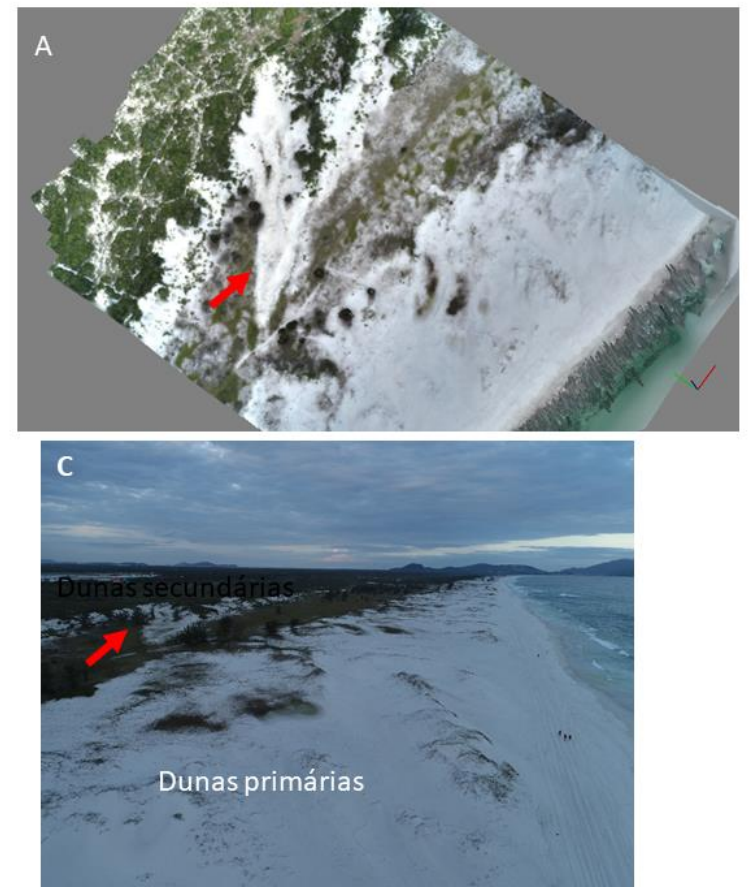

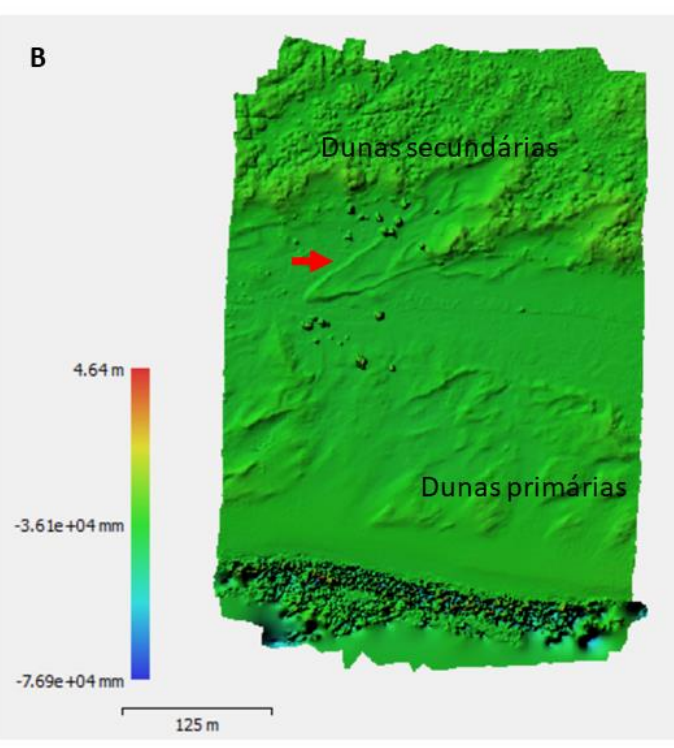

Figura 4. Sequências de registros feitos com VANT. (A) Ortomosaico mostrando as duas barreiras costeiras, em que a seta vermelha mostra a ação eólica retrabalhando sedimentos em direção a depressão entre as barreiras. (B) modelo digital de terreno, ou seja, sem que as altitudes estejam ajustadas, em que a seta vermelha mostra o resultado dessa ação formando uma feição parabólica. Nas dunas primárias notam-se depressões e entre elevações formadas por dunas frontais, de maneira que as depressões são formadas por ação hidrodinâmica de ondas em condições de tempestade. (C) fotografia oblíqua da Massambaba de maneira a se identificar dunas primárias e secundárias. 


\section{DUNAS PRIMÁRIAS EM CABO FRIO}

O arco praial de Cabo Frio (Figura 2) se desenvolve entre o Canal de Itajuru, ao norte e afloramento do cristalino ao sul, formando a retaguarda da praia, depósitos eólicos com diferentes altitudes, tendendo a aumentar volumétricamente os depósitos eólicos de sul para norte (Cardoso et al, 2018). Pereira et al (2008) identificou que a existe uma tendência da morfodinâmica de praias, se tornar dissipativa, no trecho mais setentrional da praia, em relação a parte mais ao sul. Tal tendência está associada a sedimentação cada vez mais fina na antepraia, que é a fonte de sedimentos para a praia (Pereira et al, 2008). A relação entre a morfodinâmica e a formação de dunas frontais foi bem descrita por Short e Hesp (1982), que mostraram que em praias dissipativas haveria tendência de desenvolvimento de dunas frontais, volumetricamente destacadas. Delgado-fernandez (2010) revisando os efeitos entre a formação de pista de ventos e o transporte eólico, da praia para o pós-praia, identifica que quanto mais tangencial o vento em relação ao alinhamento da linha de costa, maiores seriam os volumes transportados em direção as dunas.

Cardoso et al (2018) de fato sugerem que o alinhamento da linha de costa em relação ao vento preferencial de NE, seja um fator potencial para o desenvolvimento de diferentes feições eólicas primárias. Numa análise sobre os dados obtidos em dunas primárias em Cabo Frio, apresentados na figura 5, nota-se que existem diferentes padrões morfológicos adjacentes a praia. Na Figura 5A e 5B nota-se que os depósitos eólicos são caracteristicamente associados a lençóis de areia se deslocando em direção ao continente, num típico movimento transgressivo, porém sem ainda a possibilidade de se determinar as nuances observadas na figura 5C. É possível se verificar a formação de dunas parabólicas, transversais e barcanas (Figura 5C), além da retenção de sedimentos por ação da vegeteção, sugerindo até uma impossibilidade de limitar fisiograficamente a ocorrência de diferentes padrões eólicos. 


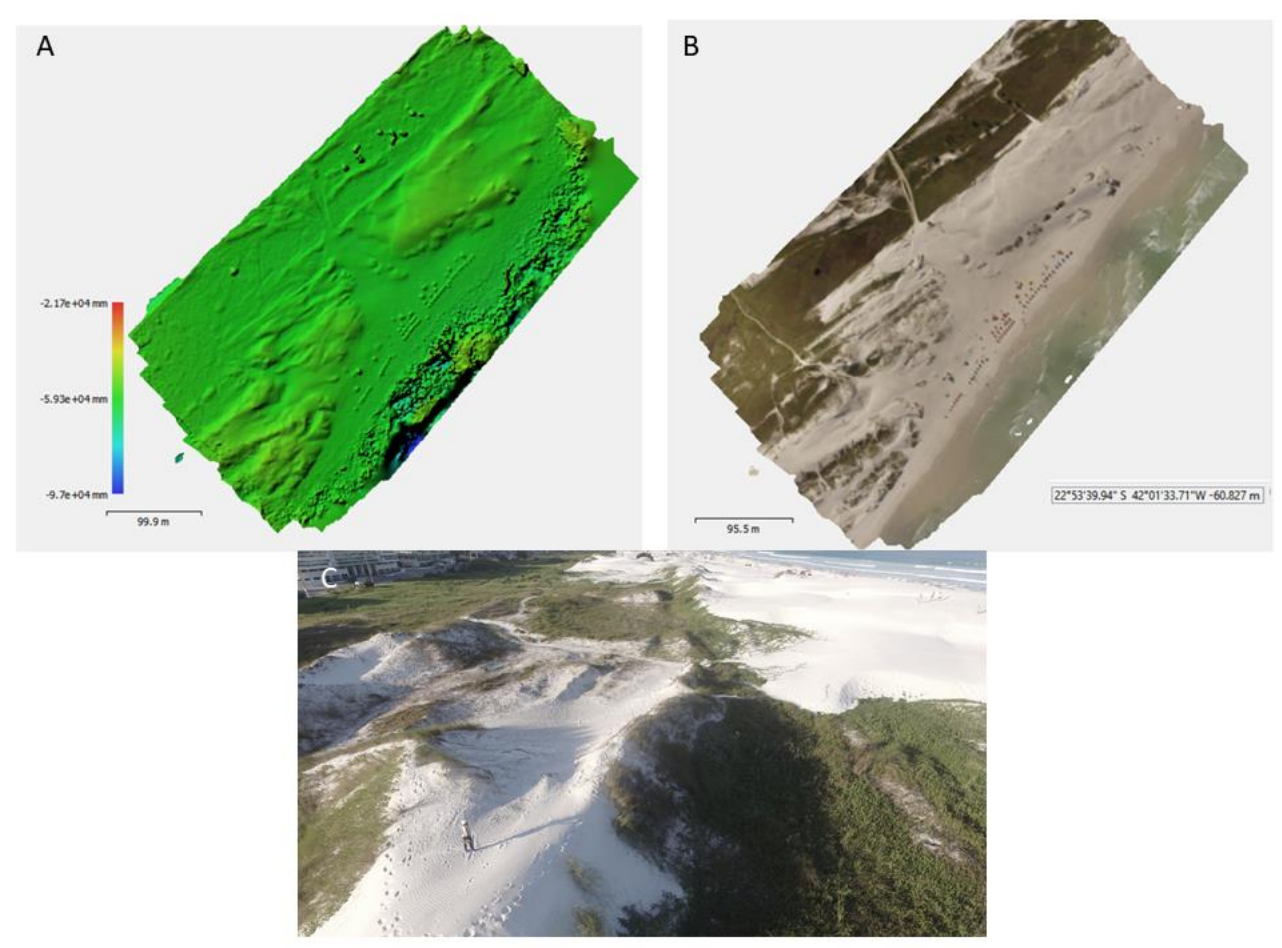

Figura 5. Dados obtidos em dunas primárias em Cabo Frio, com VANT. (A) Modelo digital de terreno, sem correção altimétrica, em se notam feições de dunas parabólicoas junto a costa, como provável retrabalhamento de dunas frontais. (B) Ortomosaico de dunas primárias em que é possível se distinguir diferentes formas eólicas, como dunas transversais, parabólicas e barcanas (C) fotografia oblíqua na Praia de Cabo Frio com feições parabólicas, transversais e barcanas.

\section{DUNAS TRANSGRESSIVAS EM MEGADUNA - CABO FRIO}

Fernandez et al (2017) baseados em dados morfométricos em campos de dunas identificou como a fisiografia mais marcante entre todos os depósitos eólicos identificados entre o Cabo Búzios e o Cabo Frio, foram feições de megadunas em formato de parabólicas. Estes depósitos se desenvolvem transgressivamente, a partir da migração de diferentes padrões morfológicos associados principalmente ao empilhamento de dunas barcanas, barcanóides e transversais, descritas apenas por dados em perfil, que de fato provam que existe tal empilhamento, em função do aumento altimétrico dos dunas e cristas marcadas pelas dunas barcanas/barcanóides.

Na figura 6 estão expostos os dados obtidos pelo VANT que apresentam uma outra perpectiva morfológica das afirmações feitas por Fernandez et al (2017), em relação a observação de diferentes formas eólicas na megaduna. Na figura $6 \mathrm{~A}$, se nota de fato a ocorrência de dunas barcanas e barcanóides, migrando em direção ao continente, soterrando a vegetação. Foram identificados na imagem (Figura 6A) formações de parabólicas, fora do 
escopo da megaduna. Na figura 6B, a morfologia das dunas transgressivas descrita fica ainda mais evidente, com as formas destacadas das feições eólicas, sugerindo a contínua evolução de dunas livres, formadas no depósito de megaduna. A figura $6 \mathrm{C}$ apenas corrobora a identificação dos modelos de terreno e ortomosaico, em se notam o padrão de dunas livres.

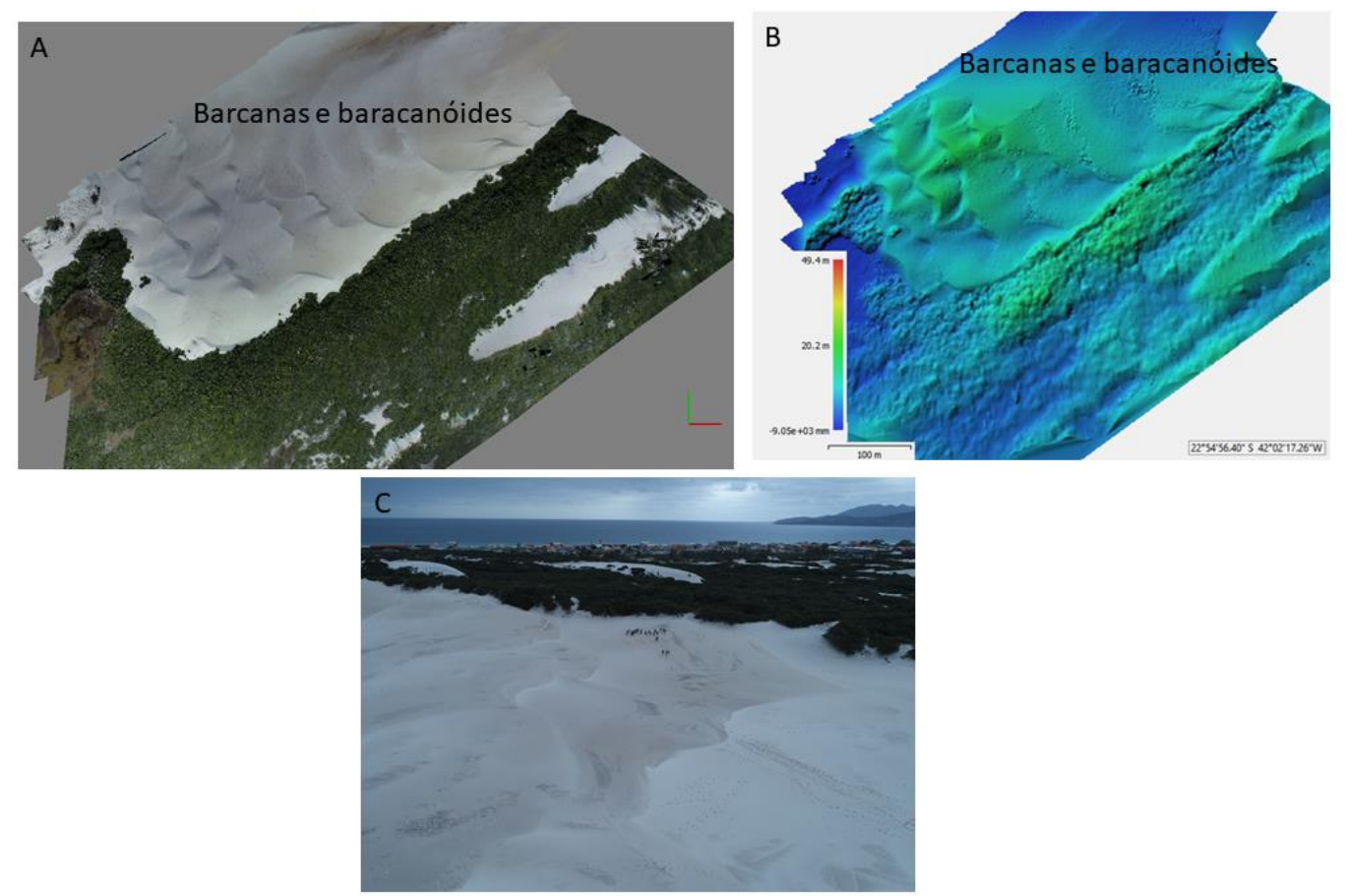

Figura 6. Dunas secundárias em Cabo Frio obtidas em uma feição de megaduna parabólica. (A) Ortomosaico de fotografias no nadir, que serviram de base para a formação de um modelo digital de elevação. Nota-se o desenvolvimento de dunas barcana e barcanóides. (B) Modelo digital de elevação em que de fato se determina a formação de tipologia de dunas livres, em sedimentação já depositada. (C) Fotografia oblíqua na meganduna em que se identifica a formação de barcana e barcanóides.

\section{DUNAS NEBKAS - CABO FRIO}

Algumas tipologias eólicas são determinadas pela ação de obstáculos, sejam eles associados a acidentes geográficos como falésias e costões, como também a vegetação. Desta forma são observadas dunas do tipo escalonares, parabólicas e nebkas, estas últimas diretamente associadas ao efeito da vegetação. Entre as dunas associadas ao efeito da vegetetação, Fernandez et al (2017) identificaram feições parabólicas e nebkas na planície costeira de Cabo Frio. A morfologia de nebkas foi descrita, por exemplo em Pye e Tsoar (2009), a partir de acumulações sedimentares circulares ou semicirculares, condicionada ao padrão vegetacional, que definiria não somente a oportunidade de fixação dos sedimentos, em função da distribuição que a vegetação apresentaria em termos espaciais, mas também em 
relação ao consorciamento de diferentes padrões florísticos, determinando morfometricamente a altitude, área, e forma das dunas.

Monteiro et al (2018) e Fernandez et al (2017) mostraram que dunas nebkas ocorrem na parte centro sul da planície costeira de Cabo Frio. Estas acumulações foram observadas a partir de feições semi-circulares fixos por vegetação (árvore focal Clusia fluminensis). Monteiro et al (2018) avança na avaliação ecológica sobre a relação vegetação com a geomorfologia, mas em função das restrições metodológicas de representação espacial, teve que restringir suas observações a poucas acumulações eólicas para a avaliação morfológica observada. Nos dados obtidos com VANT, apresentados na figura 7, nota-se uma sensível ampliação das possibilidades de caracterização deste tipo de dunas. No ortomosaico apresentado na figura 7A, pode-se verificar a distribuição espacial das diferentes moitas vegetacionais, associadas a Clusia fluminensis, que representa a árvore focal, e tem por característica suportar estress relacionado a escassez de água (Monteiro et al 2018). Na figura $8 \mathrm{~B}$, nota-se a espacialização do relevo na forma de modelo digital de terreno, em que se pode notar a distribuição espacial das moitas, e o aprisionamento pela vegetação, dos sedimentos transportados pelo vento. Na figura 7C a paisagem observada na área corroborando a morfologia observada.
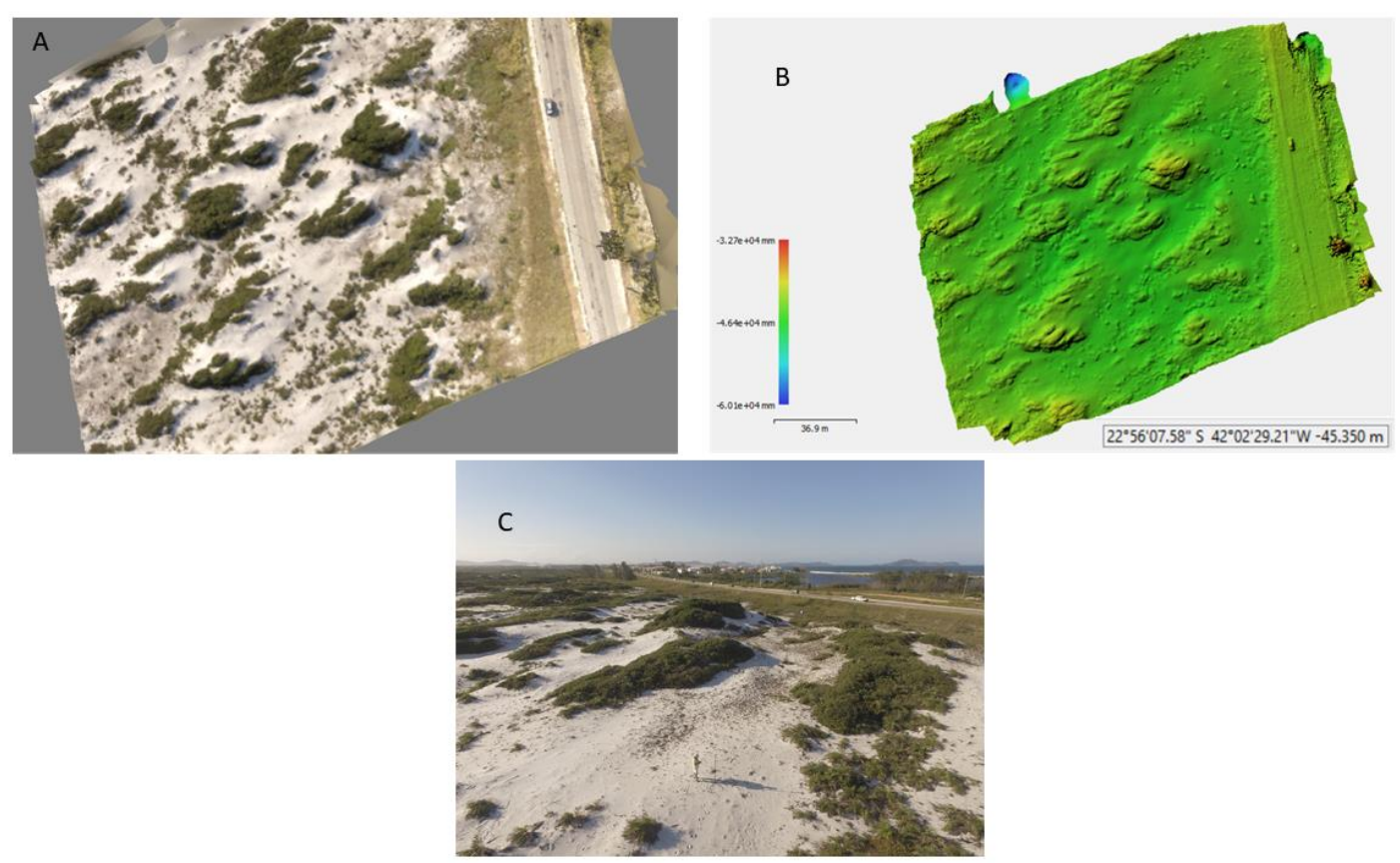

Figura 7. Dados obtidos em dunas nebkas em Cabo Frio, com VANT. (A) Ortomosaico das dunas nebkas com a distribuição vegetacionais. (B) modelo digital de elevação com as moitas marcando as irregularidades no terreno, associadas a relação entre a vegetação e a ação do 
vento. (C) A paisagem oblíqua das dunas mostrando áreas desprovidadas de vegetação, sendo a provável fonte de sedimentos para as dunas.

\section{DUNAS PRIMÁRIAS E SECUNDÁRIAS - PERÓ}

Na planície costeira do Peró as feições eólicas apresentam suas características mais preservadas pela ausência de edificações. Morfologicamente Fernandez et al (2017) identifica diferentes formas de relevo eólico, com diferentes padrões como parabólicas, escalonares, e alguns depósitos fixados por vegetação, que não apresentam quaisquer padrões possíveis de interpretação, sendo classificados como indiferenciados. O interessante de se notar, é que mesmo sendo completamente preservada, em suas características mais naturais, o Peró sofre forte pressão para ser ocupada por hotéis, condomínios residenciais e outras atividades sócioeconomicas. Na parte central da planície, Fernandez et al (2017) identificaram padrões morfológicos associados a dunas parabólicas, sepradas de um cordão de dunas frontalmente posicionadas a praia, porém com detalhamento pouco claro, em relação principalmente as dunas parabólicas e frontais.

Na figura 8 foram identificadas com números 1, associadas a dunas frontais e com o número 2, dunas que seriam secundárias. Nas dunas primárias se notam que seriam do tipo frontais, porém a continuidade do cordão dunar, é interrompida por cortes eólicos, evidentes na figura $8 \mathrm{~B}$, marcada pelo número 1 no ortomosaico (figura $\mathrm{A}$ ) e no modelo digital de elevação (figura 8B). Na planície costeira, os dados do VANT mostram a ocorrência de nuances interessantes na formação de dunas parabólicas. É interessante ressaltar que estas dunas parabólicas apresentam em diferentes partes, cortes eólicos, demostrados por feições semicirculares em diferentes pontos, fato possível de ser observado apenas com o auxílio das imagens de alta definição. 

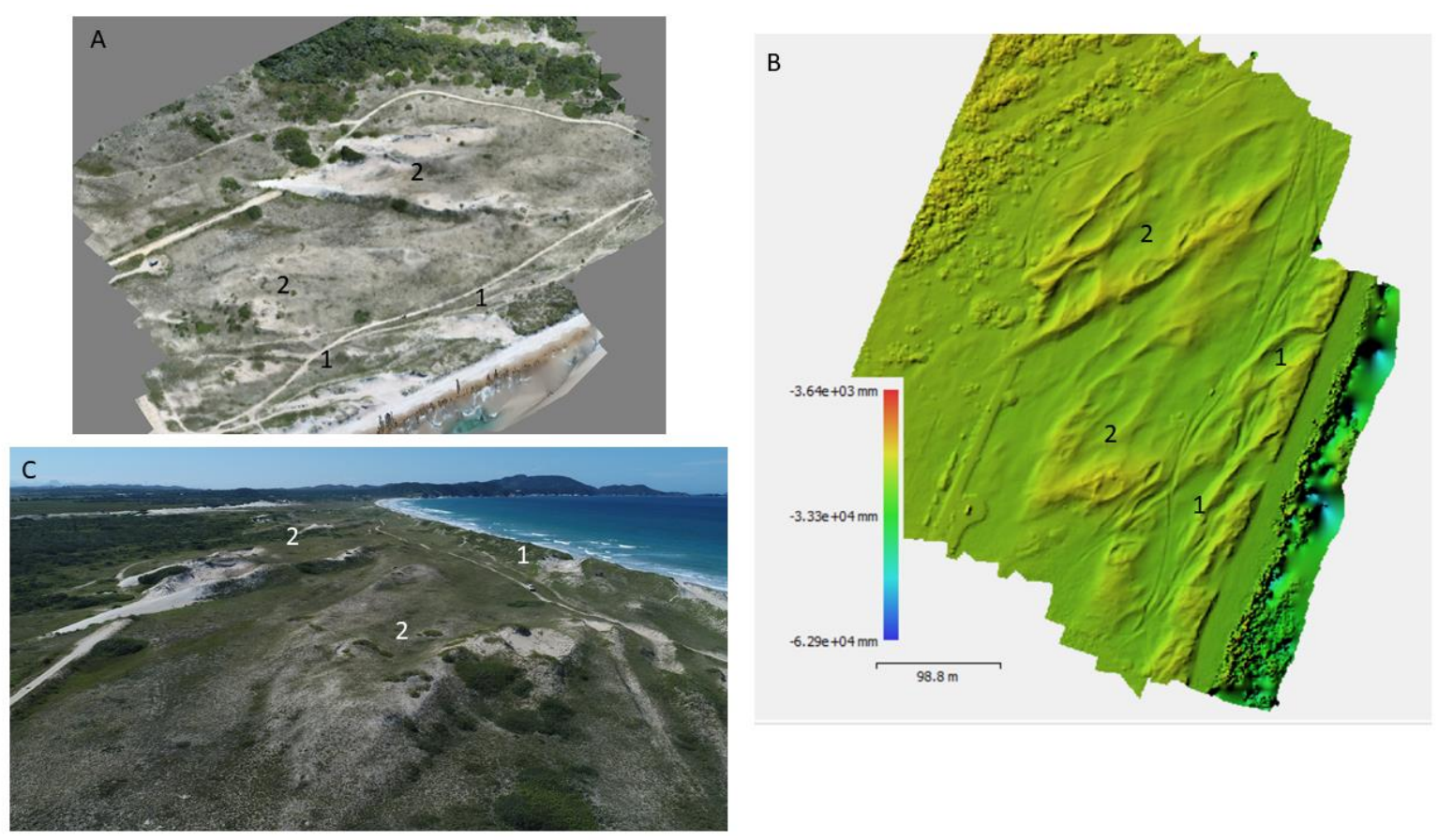

Figura 8. Dados obtidos em dunas primárias em Cabo Frio, com VANT. (A) Ortomosaico de feições eólicas na planície costeira do Peró, em se notam feições de dunas parabólicas, na planície costeira marcadas com o número 2, e dunas primárias associadas a dunas frontais, com cortes eólicos, observados com o número 1 (B) Detalhamento morfológico com modelo digital de elevação, em que ficam evidentes as formas de relevo observadas no ortomosaico. (C) fotografia oblíqua do Peró de maneira a se identificar dunas primárias e secundárias.

\section{CONSIDERAÇÕES FINAIS}

As considerações aqui apresentadas mostraram que a utilização de tecnologias associadas a imagens de alta definição obtidas por VANTs, tem um excelente potencial para a geomorfologia, com os exemplos obtidos em formas de relevo eólico. Provavelmente com a diminuição dos custos de aquisição do equipamento e dos programas de pós processamento, a utilização dos VANTs deve crescer sensivelmente na identificação detalhada das formas de relevo. Mais que apenas identificar as formas de relevo, o potencial de monitoramento evolutivo de diferentes feições fisiográficas devem crescer sensivelmente.

\section{AGRADECIMENTOS}

Esse trabalho foi construído com 10 anos de exploração de diferentes formas de relevo associadas ao vento no litoral do Rio de Janeiro, em que diversos trabalhos foram desenvolvidos, na forma de artigos, comunicações, dissertações e teses, em que vários estudantes participaram. Especificamente este artigo só foi possível pelo auxílio do estudante 
de mestrado da Universidade Estadual do Rio de Janeiro, Artur Lana, que dedicou seu tempo e equipamento para a geração das imagens aqui apresentadas. A Artur Lana meus sinceros agradecimentos. Agradeço sinceramente a organização do SINAGEO, Cariri, que sem esse convite não seria possível a realização deste trablho.

\section{REFERÊNCIAS}

CARDOSO, I. C. B. ; MONTEIRO, S. C. ; OLIVEIRA FILHO, S. R. ; FERNANDEZ, G. B. Morfodinâmica entre praia e duna em trecho exposto a ventos do mar para a terra: enfoque especial ao efeito de pista de vento - litoral de Cabo Frio, RJ. Anais do XII Simpósio Nacional de Geomorfologia - SINAGEO, 2018.

DAVIS, J. L. Geographical Variation in Coastal Development. London, UK: Longman, 1980.

DELGADO-FERNANDEZ, I. A review of the application of the fetch effect to modeling sand supply to coastal foredunes. Aeolian Research 2, 61-70. 2010.

EWING, R. C., MCDONALD, G. D., HAYESB, A.G. Multi-spatial analysis of aeolian dunefield patterns. Geomorphology, 240; 44 -53.

FERNANDEZ, G. B.; PEREIRA, T. G.; ROCHA, T. B.; MALUF, V.B. ; MOULTON, M. A.B.; OLIVEIRA FILHO, S. R. Classificação morfológica das dunas costeiras entre Cabo frio e o Cabo Búzios, litoral do estado do Rio de Janeiro. Revista Brasileira de Geomorfologia, v. 18, p. 595-622, 2017.

FERNANDEZ, G. B.; FIGUEIREDO, M. S. ; ROCHA, T. B.; MALUF, V. B. ; MARTINS, C.; MOULTON, M. A.B. Foredune Morphological Changes By Offshore Winds Revealed By Ground-Penetrating Radar: Massambaba Beach ? Rio De Janeiro, Brazil. Journal of Coastal Research, v. 1, p. 278-282, 2016.

FERNANDEZ, G. B.; MUEHE, D. Sediment budget correlation with the Southern Oscillation Index of a foredune westward of Cabo Frio (Rio de Janeiro). Journal of Coastal Research, v. SI 39, p. 1-6. 2004. 
FIGUEIREDO, M. S. ; ROCHA, T. B.; FERNANDEZ, G. B. Geomorfologia earquitetura deposicional interna da barreira costeira holocênica da Massambaba, litoral do estado do Rio de Janeiro. Revista Brasileira de Geomorfologia, v. 19, p. 447-464, 2018.

HESP, P. A. The beach backshore and beyond. In Handbook of Beach and Shoreface Morphodynamics, ed. A. D. Short. Brisbane, Australia: John Wiley and Son. 1999.

HESP, P. A. Foredunes and blowouts: Initiation, geomorphology and dynamics. Geomorphology 48, 245-268. 2002.

NOLET, C.; VANPUIJENBROEKB, M.; SUOMALAINENC, J.; LIMPEN, J. RIKSENA, M. UAV-imaging to model growth response of marram grass to sand burial: Implications for coastal dune development. Aeolian Research, 31, 50-61. 2018.

MARTINS, C. A. ; FERNANDEZ, G. B. Caracterização morfológica de depósitos gerados por transposição ocorridos em junho de 2016 na parte oriental da barreira da Massambaba RJ. Anais do XII Simpósio Nacional de Geomorfologia - SINAGEO, 2018.

MONTEIRO, S. C. ; CARDOSO, I. C. B. ; FERNANDEZ, G. B. Interação entre vegetação e geomorfologia na formação de dunas nebkas, Cabo frio, Rio de Janeiro. Anais do XII Simpósio Nacional de Geomorfologia - SINAGEO, 2018.

PEREIRA, T. G.; ROCHA, T. B.; FERNANDEZ, G. B. Geomorfologia e Morfodinâmica Costeira da Planície entre Cabo Frio e Arraial do Cabo - RJ. Anais do VII Simpósio Nacional de Geomorfologia/ II Encontro Latino Americano de Geomorfologia, Belo Horizonte. 2008.

PIÉGAY, H., KONDOLF, G.M., MINEAR, J.T., VAUDOR, L. Trends in publications in fluvial geomorphology over two decades: a truly new era in the discipline owing to recent technological revolution? Geomorphology 248, 489-500. 2015.

PYE, K., TSOAR, H.: Aeolian Sand and Sand Dunes. Springer. 2009. 
RUESSINK, B.G., ARENS, S.M., KUIPERSC, M., DONKERA J.J.A. Coastal dune dynamics in response to excavated foredune notches. Aeolian Research, 31: 3-17. 2018.

SLOSS, C.R.; SHEPHERD, M. HESP, P. Coastal Dunes: Geomorphology. Nature Education Knolodge 3 (10):2. 2012.

SHORT, A. D. \& HESP, P. A. Wave, beach and dune interactions in southeastern Australia. Marine Geology 48, 259-284.1982.

Viles, H. Technology and geomorphology: Are improvements in data collection techniques transforming geomorphic science. Geomorphology, 270; 121-133. 2015.

ZHAO, Y; Ninghua C.,*, Jianyu C., Chengqing H. Automatic extraction of yardangs using Landsat 8 and UAV images: A case study in the Qaidam Basin, China. Aeolian Research, 33; 53-61. 2018. 